\title{
O Conceito de Tecnologia em Ruy Gama
}

Igor Zanoni Constant Carneiro Leão*

Apesar da preocupação com o desenvolvimento científico e tecnológico no Brasil já ser antiga, a definição dos termos em questão e uma revisão de sua história foi realizada de modo notável pelo arquiteto Ruy Gama. Nascido em 1928, Gama teve um currículo vasto, destacando-se como historiador da técnica e da tecnologia. Sua preocupação com os termos que definem o processo tecnológico a partir dos elementos que compõem o trabalho homens, materiais, máquinas e saber, fez com que utilizasse a arte da filologia, de modo a restaurar um percurso histórico do trabalho com segurança, tornando-se uma referência obrigatória aos estudiosos dessa área.

Sua contribuição foi resumida por Maria Vilma Rodrigues Nadal: "preocupado com a essencialidade, a excelência e exatidão, buscou precisar concepções sobre a Técnica e a Tecnologia, avaliando-lhes o significado em diferentes culturas e contextos. É ele quem reitera em diversos momentos: (i) tecnologia não é mercadoria, ainda que tenha surgido no contexto conflitante do capitalismo industrial e avançado. (ii) Disse, também, ter preocupações com o uso generalizado do termo na sociedade, apelando para os conceitos genéricos que lhe adulteram o significado. (iii) Tecnologia não pode ser coisificada". Ruy Gama faleceu em 1996.

Neste texto, recuperamos alguns conceitos e teses definidas pelo autor em seu livro A Tecnologia e o Trabalho na História, originalmente uma tese de livre docência apresentada na Faculdade de Arquitetura e Urbanismo da USP em 1985. A partir daí, desejamos fazer algumas pontes entre eles e alguns aspectos no desenvolvimento tecnológico no Brasil nos últimos anos.

O primeiro ponto a destacar, após o rigoroso trabalho filológico e bibliográfico do autor, é a conclusão de que "A tecnologia moderna foi se constituindo a partir do século XVII, pari passu ao desenvolvimento do capitalismo e à substituição do modo de produção feudal/ corporativo, e do sistema de transição do conhecimento apoiado na aprendizagem, pelo emprego do trabalho assalariado e o sistema escolarizado de transmissão do conhecimento". Nesse sentido, o autor define os dois conceitos citados:

\footnotetext{
* Doutor em Economia pela UNICAMP. Professor do Departamento de Economia da UFPR. Endereço eletrônico: igorza@,bol.com.br
} 
Técnica: conjunto de regras práticas para fazer coisas determinadas, envolvendo a habilidade do executor e transmitidas, verbalmente, por exemplo, no uso das mãos, dos instrumentos e ferramentas e das máquinas. Alarga-se freqüentemente para nele incluir o conjunto dos processos de uma ciência, arte ou ofício, para obtenção de um resultado determinado com o melhor rendimento possível.

Tecnologia: estudo e conhecimento científico das operações técnicas ou da técnica. Compreende o estudo sistemático dos instrumentos, das ferramentas e das máquinas empregadas nos diversos ramos da técnica, dos gestos e dos tempos de trabalho e dos custos, dos materiais e da energia empregada. A tecnologia implica na "aplicação dos métodos" das ciências físicas e naturais e, como assinala (com propriedade, mas não com primazia) Alan Birou, também na comunicação desses conhecimentos pelo ensino técnico.

A partir dessa definição, para o autor, o conceito de tecnologia como ciência foi criado nos países nos quais o Estado teve papel importante no desenvolvimento das técnicas, da manufatura e do ensino técnico. Destaca-se aí, a França onde o Estado incentiva o desenvolvimento manufatureiro desde Luís XIV, assumindo o controle sobre o desenvolvimento da técnica e sobre o ensino das artes e das técnicas. Após a Revolução Francesa, o Estado mobiliza cientistas para o desenvolvimento da indústria com a reorganização da Academia de Ciências, Fundação da Escola Politécnica e a lei Le Chapelier, de 1791, que suprimia os privilégios das profissões e extinguia as corporações de ofício, ao mesmo tempo em que proibia a organização dos operários. O trabalho assalariado passa a ser quase a única forma de trabalho, regulada pelo mercado de trabalho; o que significa, na prática, a ditadura dos patrões e das companhias poderosas.

Essa atuação do Estado na França torna-se um paradigma para outras nações, quanto à legitimidade da subordinação da técnica à ciência. Nesse momento, a relação entre ciência e técnica é apreendida pelo positivismo, que tanta importância vai ter, por exemplo, no Brasil. A visão do positivismo é explicitada, segundo citação de Ruy Gama, por Ludovico Geymonat:

"Ainda que sustentando, como Bacon, que uma das tarefas principais da ciência consiste em aumentar o poder do homem sobre o mundo, o fundador do positivismo reduz a função da técnica a uma categoria meramente servil. Mediante a evidência das demonstrações e mediante o rigor das provas experimentais, a ciência, segundo Comte e seus contemporâneos, é capaz de conseguir leis dotadas de validade absoluta e irreformável; a técnica não tem, pois, nenhuma iniciativa específica senão e apenas a tarefa de aplicar com o 
maior escrúpulo os ditames inequivocamente estabelecidos pela investigação científica. Quanto melhor saiba ater-se a eles, melhor conseguirá formular e resolver todos os problemas particulares suscitados pela prática. Melhor dizendo: para transformar eficazmente o mundo, a técnica tem que se limitar a tomar da ciência as diretrizes do seu trabalho."

Essa subordinação da técnica à ciência não é mais tão aceita, uma vez que a história não permite verificar a concepção de que a técnica não é mais do que aplicação de ciência. $\mathrm{Na}$ verdade, a relação entre ciência e técnica é, antes, de mão dupla. A tecnologia pode ser entendida, a partir daí, como um saber que se distingue da ciência pelo seu objeto - realidade técnica - mas que é ciência pelo seu espírito, seja pelo método com que coloca os problemas; seja pela preocupação em exprimir o que a técnica faz pelo seu rigor; seja pela generalização dos conceitos com que trabalha e pelo uso que faz da matemática, assim como pela precisão de suas observações e mensurações. Essa é a visão, por exemplo, do pesquisador Bertrand Gille, hoje bastante difundida.

Todavia, o sentido do termo tecnologia, com o discurso racional sobre a atividade técnica, deve-se ao filósofo e matemático alemão Christian Wolff, para quem "a tecnologia é, portanto, a ciência das artes e das obras-de-arte, ou se preferirmos, ciência das coisas que o homem produz com o trabalho dos órgãos do seu corpo, principalmente com as mãos". A tecnologia seria para Wolff uma ciência entre as outras, estruturada a partir dos princípios da física experimental, como estudo das regras operatórias e das obras, a exemplo da arquitetura civil e da agricultura.

Essa preocupação deu origem a uma linguagem tecnológica e a um repertório de conceitos como os de fábrica, isto é, os lugares de trabalho em que se usam, sobretudo, o fogo, o martelo e a manufatura, em que se faz uso principalmente das mãos, caracterizando-se pela elaboração de materiais de origem animal e vegetal. A manufatura também é entendida como um lugar onde se desenvolve trabalho em cooperação, distinguindo-se do trabalho domiciliar. Os autores aí, segundo Ruy Gama, tateavam o caminho, destacando ora a força de trabalho, ora o objeto de trabalho ou o meio de trabalho, evidenciando-se muitas vezes o aspecto espacial.

Essa preocupação terminológica anda paralela com o desenvolvimento das escolas técnicas artesanais e da ciência experimental. Muitas vezes, lutando contra as escolas clássicas. Há também uma preocupação de educar as crianças pobres de maneira conseqüente, seguindo uma ética do trabalho, criando-se, por exemplo, orfanatos sob esse desígnio. Mesmo assim, durante um bom tempo na Europa, a transmissão de homem para homem da habilidade no 
trabalho teve uma importância maior do que o treinamento formalizado de mecânicos e engenheiros nas escolas técnicas.

A tecnologia moderna, na verdade, entra na fábrica junto com as máquinas, referindo-se ao conjunto do processo produtivo, cujo saber escapa do trabalhador individual desindividualizado. Essa nova tecnologia tem como objeto a disciplina e os controles de tempo e de produtividade, propondo um aperfeiçoamento técnico aos ofícios. Nesse sentido, para um autor como Beckmann, a tecnologia é uma ciência que ensina como tratar os produtos naturais e o conhecimento dos ofícios.

O desenvolvimento na Alemanha também se apóia no Estado, uma vez que o próprio Estado alemão vincula a Universidade ao desenvolvimento tecnológico. Além disso, a tecnologia na Alemanha joga um papel interessante, porque nos estágios iniciais do capitalismo alemão havia um estado avançado de ciência teórica. Essa observação é de Braverman e explica como se dá o encontro da ciência com a técnica e a produção, dentro do caráter específico do capitalismo alemão.

O desenvolvimento da tecnologia a partir do século XVIII tem um ponto de apoio na arquitetura e na geometria que ela começa exigir, dando origem à estereotomia, isto é, "a teoria e prática do corte da pedra e da madeira para construção de abóbadas e outras partes dos edifícios civis e militares", segundo Amèdée François Frezier, ou melhor, o uso na arquitetura da estereotomia, que é geometria aplicada à arquitetura e especialmente ao corte de pedras. Essa técnica, apoiada na matemática, permitia a representação gráfica das peças a serem cortadas e a divisão do trabalho em várias etapas: a primeira delas, a representação gráfica - própria solução geométrica dos problemas; segue-se o corte das pedras e das madeiras; logo, a etapa de assentamento das pedras ou de montagem das estruturas de madeira. Como indica Ruy Gama:

"Dividido desta maneira, o trabalho pode ser desenvolvido por vários profissionais ao mesmo tempo, e não precisa ser totalmente executado pelo mesmo artesão. Um arco, por exemplo, cortadas na pedra suas aduelas, pode ser montado por um ou por vários pedreiros, não sendo, nenhum deles, necessariamente um dos que talhou a peça de pedra. Criam-se dessa maneira condições para reunião de um grande número de artesãos no mesmo canteiro, produzindo com maior rapidez obras que individualmente executadas gastariam um tempo muito maior. A geometria forneceu os elementos para organização do trabalho em moldes que se assemelhavam aos da manufatura em geral". 
Embora o ferro fundido nasça no final do século XVIII, com a aplicação da esteriotomia em pontes, o uso da pedra na construção de grandes pontes, viadutos e outras obras persiste até o século XIX. A importância da matemática aí aplicada não pode ser separada da habilidade no desenho técnico e mecânico. Aí, aparentemente, se dá "uma transição" da técnica para tecnologia. É impossível também separar, como já havia notado Adam Smith, a penetração dos mecanismos no meio artesanal da dissolução do poder das corporações, ao mesmo tempo em que essas mesmas corporações tinham, por exemplo, na França, forte apoio no antigo regime. É fácil ligar a ascensão de uma burguesia assentada nos mecanismos e nas máquinas ao novo regime político.

A relação entre o nascimento da tecnologia e da matemática aplicada não deve obscurecer o fato de que a tecnologia exige o encontro da teoria com a prática, mas não se resume a isso, pois está ligada desde o seu nascimento à alteração do modo de produção e às formas de aquisição e transmissão dos conhecimentos técnicos. Nota-se também que as matemáticas práticas se desenvolvem rapidamente a partir do desenvolvimento das atividades mercantis, a partir do século XIII, assim como as técnicas da mineração e metalurgia, da química e da agricultura e outros estudos baseados no desenho como a anatomia, a zoologia e os herbários. Neste desenvolvimento econômico que vai desembocar na Renascença, um momento importante é o encontro da ciência como a trigonometria com novas exigências de ordem técnica, ligadas a experiência, como vai ocorrer com as navegações a partir do século XV. Como indica Ruy Gama:

“A experiência era, para os navegadores, o critério de verdade. Com ela contestaram os antigos conhecimentos da geografia. Não era experiência organizada e provocada com base numa teoria e destinada a comprová-la ou negá-la, que é o que se estabelece com Galileu; mas é a vivência e a visão dos aventurosos capitães, à qual não estava, no entanto, alheia a ciência: Foi alma a Sciencia, e corpo a ousadia da mão que desvendou...escreve o matemático cientista Pedro Nunes".

O contato entre a técnica e a ciência se dá em várias frentes, como no comércio, na organização de empresas e das formas de associação capitalista, da contabilidade e até dos seguros, apoiados no cálculo de probabilidade. Entretanto, nosso autor é enfático ao dizer que a tecnologia não surge apenas desse aumento do saber, mas das alterações mais profundas, não só no desenvolvimento das forças produtivas, mas também nas relações de produção. É nesse contexto que o ensino profissional se afirma a partir do século XVII marcado por uma função empírica e utilitária. Os autores dessa época enfatizam que "só a 
prática faz os artistas", preocupando-se tanto com o ensino dos "cavalheiros" como com escolas de trabalho para os pobres, destinadas a criar neles hábitos de ordem de disciplina e de sobriedade.

Começa a firmar-se nesse momento a passagem da transmissão do saber, imediatamente ligado à prática de uma arte ou um ofício, para a escolarização desse processo de formação da força de trabalho. $O$ ensino, que na tradição humanista literária ainda permanecia verbal e filológico, passa desde Bacon a aconselhar o estudo da natureza, iniciando-se uma educação técnica que dá a mão a uma pedagogia da ética do trabalho para as classes laboriosas. Também no Brasil colonial se nota, já perto da independência, preocupações com essa ética, como se revela num relato escrito em 1807, por ordem de Dom João VI.

Há preocupações com a vadiagem, sugerindo-se inclusive a supressão dos mosteiros e sua transformação em casas de educação para pobres, órfãos, ignorantes e até filósofos, para que pudessem meditar sobre a natureza livre dos cuidados materiais. Essa preocupação se justifica especialmente quando se percebe que as artes de ofícios no Brasil desde o século XVI podiam ser resumidas à escultura e à talha, presentes na obra do Aleijadinho, na de Manoel da Costa Ataíde e de alguns artistas que trabalhavam com a escultura, a fundição, a construção de edifícios e peças de porcelana. Mas é só em meados do século XIX, após a independência, a impossibilidade de acesso dos brasileiros à universidade portuguesa e a extinção das corporações de ofício, é que se concretizam medidas para transmissão de um saber fazer escolarizado. Essa preocupação se acentua, já próxima à república, com a criação do Instituto Agronômico de Campinas, do Instituto Butantã, da Escola Superior de Agricultura Luiz de Queiroz, e já em 1940, da Associação Brasileira de Novas Técnicas.

Esse trabalho de reconstituição histórica mostra a própria historicidade da tecnologia, que se transforma com o modo de produção e só adquire suas significações em sua vinculação com as mesmas. A tecnologia não é autônoma em relação à prática, como se a história da técnica pudesse ser vista como história da mecânica aplicada ou da química aplicada. A seguinte afirmação resume a visão do autor: "A tecnologia deve ser entendida em suas relações históricas com a produção, na qual se integra, e com as teorias e métodos que, como ciência que é, aplica e realimenta". Nesse sentido, a tecnologia vincula-se intimamente à práxis social, associando-se às ações políticas.

Tomando-se como centro da investigação essa práxis social, o autor nota que o Brasil é um país com inúmeros resquícios coloniais. Na sua formação, a divisão entre artes 
mecânicas e artes liberais reduziu-se a uma divisão brutal entre escravos e senhores, na qual aos primeiros se impunha a produção; aos últimos, o mando, a palavra e o pensamento, desde que não confrontasse com a metrópole. A independência não foi realizada inteiramente, não se aboliu com ela a escravidão, e a república também aguarda novas virtualidades. A tecnologia nacional se faz de forma limitada. Preferimos comprá-la e negar apoio aos que se lançam de inventar, de projetar e de fazer. Entretanto, essa ousadia de pensar e fazer a cultura material é caminho obrigatório para a independência. Nesse sentido, a questão tecnológica vincula-se principalmente à prática política e à formação da nação. Há ainda uma relação obrigatória entre independência tecnológica e relação de produção:

"As considerações que já fizemos acerca dos vínculos entre a tecnologia, como integrante das forças produtivas, e as relações de produção, não deixam dúvida que não creio em independência tecnológica apoiada na exploração brutal do trabalho. Não devem deixar também dúvida de que a questão não é apenas do discurso tecnológico e de uma linguagem de venda de tecnologia aos países em desenvolvimento. Não levamos a semântica a esse nível. Essas coisas têm base real e efetiva no próprio processo do desenvolvimento do capitalismo monopolista, que cria, para dela servir-se, uma linguagem mistificadora".

O discurso do autor toma um sentido claramente político. O discurso colonizador imposto ao gentio na colônia se reproduz no discurso tecnológico com o sentido colonizador dado pela idéia de "um mundo só". Como indagação provocativa e estimulante, é preciso saber se são possíveis graus de liberdade no mundo onde a cultura material está despersonalizada, alienada e delegada ao sistema de comunicação que supera a diferença das línguas e dos espaços nacionais.

Façamos agora algumas considerações sobre o texto de Ruy Gama acima apresentado. Em primeiro lugar, o autor trabalha o conceito de tecnologia utilizando a história, referindo-se aos discursos que envolvem o tema em cada época, e também situando essas definições e discursos no longo processo de nascimento de uma sociedade mercantil que se inicia, a rigor, no século XIII, atinge um ápice no Renascimento e amadurece com o revolucionamento dos processos produtivos, através da fábrica e da máquina, no que ficou conhecido como Revolução Industrial, entre finais do século XVIII e início do século seguinte.

Essa forma de trabalhar evita definições descontextualizadas e não históricas, permite também, um rigor quando se pensa seja no capitalismo moderno, seja nos seus elementos constitutivos, a saber, a relação social entre o capital e o trabalho ou entre o capital 
e o conjunto da sociedade, seja no contínuo avanço das forças produtivas que se dá, nesse modo de produção, através do amálgama entre capital e ciência e entre ambos e a técnica. A tecnologia se constitui nessas relações como peça de acumulação do capital.

Em segundo lugar, o autor se situa na corrente, bastante plural, do nacionalismo que presidiu as grandes transformações no capitalismo brasileiro, entre 1930 e 1980. Fica clara no texto a visão da tecnologia como um produto, cujo acesso ocorre de modo desigual entre os países do centro e os da periferia. Essa idéia, bastante cara ao pensamento crítico brasileiro, coloca a tecnologia como um instrumento de dominação do centro sobre a periferia.

A luta pela industrialização do país a partir de 1930, num ambiente de tecnologia estável, foi, ao mesmo tempo, uma luta pela soberania nacional. Nota-se no texto um desencanto com a crise econômica aberta nos anos finais da ditadura, bem como com os descaminhos da Nova República que a sucedeu. Esses descaminhos se agravam com uma nova fase do capitalismo mundial, marcada pelo que o autor chama "telemática" e que resume a mundialização do capital que dá seus primeiros passos entre as décadas de 70 e 80. Para Ruy Gama o processo de industrialização brasileira entra nesse período em cheque, e um dos motivos para isso é a desigualdade no acesso aos avanços recentes na ciência e na técnica, isto é, um agravamento das distâncias econômicas e sociais entre centro e periferia.

Pode-se inferir que o autor pensa a nação como um projeto de construção de laços de solidariedade entre as classes, através de uma cultura comum, em que se desdobra num país que seria marcado pela soberania, igualdade social, industrialização e autonomia tecnológica. A crise que o autor tem diante dos olhos parece-lhe por em cheque todos esses pontos. Nesse sentido, seu livro narra a tragédia da atualidade capitalista brasileira. Essa crise é tanto mais grave quanto lhe parece desarticulado o Estado brasileiro no período chamado Nova República, entre outras razões porque o Estado sempre esteve à frente do desenvolvimento tecnológico, seja diretamente através de suas empresas, seja através de financiamento.

Vamos agora recolocar algumas informações acerca dos pontos acima. Para Nancy Stepan, o que se observa de avanço técnico e científico centra-se, em grande parte, a partir da proclamação da República, com o Instituto Butantã e Manguinhos, integrando o recrutamento de pessoal, relação de cliente com Estado e produção de ciência experimental. Com a República, há um embrião unindo ciência e indústria, abrangendo o sistema industrial, universidades e instituto de pesquisa como o Butantã e Manguinhos. Os esforços aí iniciados prosseguem na primeira República com as expedições do general Rondon ao estado do Mato 
Grosso e do Amazonas, obras sobre as culturas indígenas, a fundação de faculdades e universidades, destacando-se a faculdade de medicina de São Paulo, a Universidade Federal do Paraná, a Universidade do Brasil, a Universidade de São Paulo, seguidas da fundação do IBGE.

Ocorrem avanços no saneamento urbano, na construção de estradas, na siderurgia, na indústria química, abrangendo cimento, alimentos, fármacos e produtos químicos; na construção civil, com o uso de concreto armado e os primeiros arranha-céus, e nas comunicações. $\mathrm{Na}$ área biomédica, deve-se citar também o Instituto Agronômico de Campinas, o Laboratório de Ensaio de Materiais, o Instituto de Pesquisa Tecnológico e o Serviço Geológico e Mineralógico.

Após a Segunda Guerra, a busca e a discussão da realização da independência e do desenvolvimento econômico nacional apresenta feitos como a criação da Sociedade Brasileira para o Progresso da Ciência, que se destaca tanto por sua revista Ciência e Cultura como pela discussão da Lei de Diretrizes e Bases da Educação, e ainda pela polêmica acerca de uma política científica estimulando a ciência básica além da aplicada. Essas discussões deram origem ao Conselho Nacional de Pesquisa e ao Centro Brasileiro de Pesquisas Físicas, que projeta mundialmente o físico César Lattes.

A expansão da infra-estrutura produtiva brasileira envolveu debates políticos sobre o projeto nacional-desenvolvimentista e resultou na tecnologia de construção de grandes barragens, na necessidade de desenvolvimento tecnológico e na ampliação do sistema educacional, bem como na formação de um sistema estatal de financiamento e organização da pesquisa científica, com órgãos federais e fundações nos Estados, destacando-se a Fapesp.

A história da ciência no Brasil teve um auge com Fernando de Azevedo na USP, estudando a nossa tradição em diversas áreas. Depois desse autor, na USP, na PUC-SP, na Unicamp, no Instituto Oswaldo Cruz e na Sociedade Brasileira da História da Ciência, destaca-se, na história da técnica, Milton Vargas, da Escola Politécnica, e Ruy Gama, da Faculdade de Arquitetura da USP. Tomando-se um autor num texto relativamente recente, Henrique S. Carneiro, ele terminava um texto sobre a história da ciência que utilizamos, em parte, da seguinte forma:

" $\mathrm{Na}$ atualidade, a pesquisa científica brasileira encontra-se, em muitas áreas, na condição de viabilizar-se como uma ciência nacional independente, das quais uma das mais marcantes é a da Genômica, com os projetos de mapeamento do genoma do amarelinho (Xilella fastidiosa), assim como o do câncer. A existência de uma importante base industrial e de 
núcleos avançados de pesquisa oferece condições de elaboração de um projeto de desenvolvimento planejado para o país para o qual a pesquisa científica deve ser um indispensável pilar”.

Evidentemente, os baixos níveis de investimento e de crescimento do PIB nos anos 80 em diante criaram um sério problema para a perspectiva acima esboçada por esse autor, tanto mais que os fundos públicos diminuíram e grandes empresas, não apenas estatais, mas também empresas privadas nacionais, foram desnacionalizadas nos anos 90. Além disso, essas empresas, como qualquer grande empresa, trabalham hoje com uma lógica interna e externa de produção e pesquisa muito diferente daquela adotada, entre 1945 e 1980. O próprio custo elevado da pesquisa científica na atualidade tem favorecido a reunião de grandes empresas em novas, tornando num sonho um avanço em muitas linhas. Nesse sentido, deixamos em aberto a questão, sem esquecer o eco crítico e premonitório de Ruy Gama.

\section{Referências Bibliográficas}

GAMA, Ruy. A tecnologia e o trabalho na história. São Paulo: Nobel: Editora da Universidade de São Paulo, 1986.

NADAL, Maria Vilma Rodrigues. Tributo a Ruy Gama (1928-1996); in: www.ppgte.cefetpr.br

CARNEIRO, Henrique S. História da ciência, da técnica e do trabalho no Brasil. Nuevo Mundo Mundos Nuevos. $\mathrm{n}^{\circ} 2$ Ano 2002.

MARTINS, Roberto de Andrade. Bases de dados sobre história da ciência da técnica em Portugal e Brasil, do Renascimento até 1900, comunicação apresentada no VI Encontro da Sociedade Brasileira de História e Computação. Novembro de 1996. 